\title{
Functional Adaptation of Nephrons in Dogs with Acute Progressing to Chronic Experimental Glomerulonephritis
}

\author{
Jon P. WAGNILD and Frank D. Gutmann with the technical assistance of \\ BARBARA IMM \\ From the Department of Medicine and Nephrology Section, Veterans \\ Administration Hospital and University of Wisconsin, \\ Madison, Wisconsin 53705
}

A в S T R A C T Although a diminished fractional excretion of sodium $\left(\mathrm{FE}_{\mathrm{Na}}\right)$ is the hallmark of acute proliferative glomerulonephritis (APGN), an enhanced natriuresis per glomerular filtration rate (GFR) in the chronic phases of this disease has been reported. We studied this adaptive response utilizing two different split-bladder dog models with unilateral, and a third group of dogs with bilateral Masugi's nephritis.

Group I. Six dogs with unilateral nonaccelerated APGN studied a mean of 6 days after induction had a mean base-line APGN/intact kidney GFR of $31 / 50 \mathrm{ml} /$ $\min (P<0.005)$ and $\mathrm{FE}_{\mathrm{Na}}$ of $0.2 / 0.75 \%(P<0.005)$. Acute volume expansion caused a smaller absolute increase in $\mathrm{FE}_{\mathrm{Na}}$ from the APGN kidney, $1.6 \%$, than from the intact kidney, $4.0 \%,(P<0.01)$. Maximum tubular secretion of $\rho$-aminohippuric acid/GFR (T $\mathrm{TPAH}_{\mathrm{PA}} / \mathrm{GFR}$ ) measured in three dogs was higher in the APGN kidney than intact kidney, 13.1 vs. $9.3 \mathrm{mg} / \mathrm{dl}$. Subsequent studies on three of the six dogs when the disease had become chronic demonstrated a reversal in the pattern of sodium excretion in response to volume expansion.

Group II. Six dogs with accelerated unilateral APGN (dogs presensitized to antibody source) studied a mean of 5 days after induction had a mean base-line APGN/ intact kidney GFR of $16 / 57 \mathrm{ml} / \mathrm{min}$ and $\mathrm{FE}_{\mathrm{Na}}$ of 0.22 / $0.12 \%(P>0.1)$. Contrary to group $\mathrm{I}$, volume expansion caused a greater absolute increase in $\mathrm{FE}_{\mathrm{Na}}$ from the APGN kidney, $5.8 \%$, than from the intact kidney, $2.9 \%(P<0.05)$. T $\mathrm{m}_{\mathrm{PAB}} / \mathrm{GFR}$ studied in four dogs was similar for both kidneys, 17.9 and $18.5 \mathrm{mg} / \mathrm{dl}$ for the APGN kidney and intact kidney, respectively.

This work was published in part in abstract form in 1973. Abstracts of the American Society of Nephrology. 6: 110.

Dr. Gutmann's present address is: Department of Medicine, Mount Sinai Medical Center, Milwaukee, Wis. 53201.

Received for publication 21 April 1975 and in revised form 2 February 1976.

The Journal of Clinical Investigation Volume 57 June 1976.1575-1589
Group III. Sequential studies were performed on seven dogs with bilateral nonaccelerated APGN. Initially each demonstrated sodium retention and a smaller absolute increase in $\mathrm{FE}_{\mathrm{N}_{\mathrm{a}}}$ in response to volume expansion compared to a predisease control study. With disease progression, volume expansion induced a greater absolute increase in $\mathrm{FE}_{\mathrm{Na}}$ than in the control study.

We conclude that $(a)$ the fractional excretion of sodium from the APGN kidney will be less or greater than the contralateral intact kidney or control study depending on the severity and/or chronicity of the disease, possibly as the result of morphologic alterations; $(b)$ the degree of extracellular fluid volume expansion is an important variable influencing similarity of glomerulotubular balance between the APGN and contralateral intact kidney; and (c) the "intact nephron hypothesis" applies in a limited fashion to kidneys with APGN in the absence of volume expansion just as it does for kidneys with chronic glomerulonephritis or pyelonephritis.

\section{INTRODUCTION}

Kidneys in patients with acute proliferative glomerulonephritis (APGN) ${ }^{1}$ classically exhibit increased tubular activity relative to the variable reduction in glomerular filtration rate as evidenced by sodium and water retention. Clinical reports indicate that other tubular functions such as secretion of $p$-aminohippuric acid (PAH) and reabsorption of glucose also decrease less than the glomerular filtration rate after acute glomerular injury (1-4). In contrast, Schacht et al. recently reported that patients studied months to years after an episode of acute

\footnotetext{
${ }_{1}^{1}$ Abbreviations used in this paper: APGN, acute proliferative glomerulonephritis; GFR, glomerular filtration rate; $\mathrm{C}_{\mathrm{P} \mathrm{AH}}$, clearance of $\rho$-aminohippuric acid; $\mathrm{FE}_{\mathrm{Na}}$, fractional excretion of sodium; $\mathrm{Tm}_{\mathrm{PAH}}$, maximum tubular secretion of $\mathrm{PAH}$.
} 
poststreptococcal glomerulonephritis have exaggerated salt loss after volume expansion compared to normal controls (5).

Functional alterations resulting from immunologically induced glomerular injury have received only limited attention despite extensive use of these animal models to investigate the various mediators of damage. Lubowitz et al. (6) showed that rats with nephrotoxic nephritis were able to maintain sodium balance when studied approximately 4-6 wk after the initial injection of nephrotoxic serum. Glucose titration curves on these rats were also normal (7). They, as well as Allison et al. (8), found that glomerulotubular balance in the proximal tubule was well maintained but that the fractional excretion of sodium $\left(\mathrm{FE}_{\mathrm{Na}}\right)$ was increased despite a decreased single nephron glomerular filtration rate (GFR). Disease in these animals was severe as indicated by a marked reduction in GFR and histologic changes consisting of glomerular, interstitial, and tubular damage. On the other hand, Godon has reported that rats with mild nephrotoxic nephritis of 4- to 8-wk duration have a lower base-line fractional excretion of sodium and a smaller increase in sodium excretion after volume expansion than normal controls (9). Histologic changes in these rats were limited to the glomeruli.

We have recently reported glomerulotubular balance ${ }^{2}$ is similar for the remaining functioning nephrons in the chronically diseased glomerulonephritic kidney and the contralateral intact kidney in the dog model with unilateral disease (10). Sodium excretion and $T_{\mathrm{PAB}}$ and reabsorption of glucose per GFR were similar in both kidneys of these dogs when studied in a nonvolume-expanded nonuremic environment. Similarity of glomerulotubular balance in the diseased and intact kidney, however, is altered by extracellular fluid volume expansion. Both the chronically diseased glomerulonephritic and pyelonephritic kidney exhibit an exaggerated natriuresis per GFR compared to the contralateral intact kidney in response to an acute saline load $(10,11)$. This suggests either that the change in internal milieu of the diseased kidney renders it more responsive to changes in oncotic or hydrostatic pressure in the peritubular capillaries, or that the chronically diseased kidney is more sensitive to a natriuretic substance released during volume expansion.

In this study we analyzed glomerulotubular functional relationships in kidneys with acute diffuse glomerular damage of varying severity and observed their functional progression with time, both during base-line and volumeexpanded states. Three different dog models with acute nephrotoxic nephritis were studied. In two of these models injury was limited to one kidney, the contralateral

\footnotetext{
${ }^{2}$ In this text, glomerulotubular balance refers to the ratio of tubular function/GFR for the whole kidney.
}

kidney being protected to maintain a nonuremic environment and serve as a functional and histologic control. These dogs had a split bladder with externally draining cystostomy tubes enabling simultaneous urine collection from both kidneys. For comparison, bilateral kidney damage was induced in a third model.

\section{METHODS}

In the first model, group I unilateral acute proliferative glomerulonephritis, non-accelerated, six dogs with unilateral nephrotoxic nephritis were followed during the gradual progression of their disease process. Because of time limitations imposed by obstructive complications developing from the split bladder and externally draining cystostomy tubes, we were able to follow only a limited number of dogs from acute-to-chronic stages of their nephritis to observe the changing patterns of sodium excretion. Therefore, in the second model, group II unilateral acute proliferative glomerulonephritis, accelerated, the development of nephrotoxic nephritis was accelerated by presensitizing six dogs to sheep IgG (4 mg in complete Freund's adjuvant intramuscularly), the animal source of our nephrotoxic serum. This was given 1 wk before unilateral injection of nephrotoxic serum. These dogs were thus exposed to the combined immunologic damage of both the heterologous (sheep antidog glomerular basement membrane) and autologous (dog antisheep immunoglobulin) phases of nephrotoxic nephritis causing immediate and severe damage. Finally, in group III bilateral acute proliferative glomerulonephritis, sequential studies were performed on eight dogs given nephrotoxic serum intravenously, causing bilateral disease.

Details of our method of inducing unilateral nephrotoxic nephritis in mongrel bitches is described elsewhere (12). In brief, utilizing an in vivo kidney isolation technique, we injected approximately $10 \mathrm{ml}$ of sheep nephrotoxic serum into the left artery of dogs not sensitized to sheep IgG while only $0.5 \mathrm{ml}$ was utilized in presensitized dogs. All dogs had undergone a bladder-splitting operation with insertion of externally draining cystostomy tubes at least $2 \mathrm{wk}$ before the induction procedure (13). This operation permitted simultaneous collection of urine from both kidneys. Each dog underwent a base-line study to ensure similarity of function in the two kidneys before nephrotoxic serum injection. The potency of our antiserum was only empirically quantitated.

Group III dogs with bilateral nephrotoxic nephritis received from 10 to $20 \mathrm{ml}$ of nephrotoxic serum intravenously depending on the severity of lesion desired. Before injection of nephrotoxic serum each dog underwent a base-line study. Sequential studies were then performed to observe the evolutional pattern of sodium excretion with progression of the glomerulonephritis. Dogs were studied usually twice during the 1st wk and weekly thereafter. A minimum of 2 days rest occurred between all studies with two exceptions. These dogs were not on a fixed salt intake.

For comparison with the group III dogs with bilateral nephrotoxic nephritis, acute pyelonephritis was induced in four dogs utilizing the method described by Beeson et al. (14). The kidneys were exposed through a midline incision. Multiple punctures of both kidneys were made with a hot cautery needle, the number of punctures depending on the severity of damage desired. The following day a broth containing approximately $1 \times 10^{\circ}$ Escherichia coli was administered intravenously. 
All dogs were studied while standing in a loosely supportive sling. An i.v. catheter was placed in the fore leg for infusion of the prime and sustaining solution and in the hind leg for blood sampling. Food and water were withheld for 16-18 $\mathrm{h}$ before each study with the exception that free access to water was permitted before $\mathrm{T}_{\mathrm{PAH}}$ studies.

Protocols for the various studies were as follows:

Base-line and extracellular fluid volume expansion. After base-line bloods, a priming dose of creatinine and $\mathrm{PAH}$ was administered followed by a sustaining solution of $3 \mathrm{~g} / \mathrm{dl}$ mannitol at $0.25 \mathrm{ml} / \mathrm{kg}$ per min containing creatinine and $\mathrm{PAH}$ in concentrations sufficient to maintain the serum creatinine concentration at $7-10 \mathrm{mg} / \mathrm{dl}$ and serum $\mathrm{PAH}$ concentration at $1-2 \mathrm{mg} / \mathrm{dl}$. After a 45-min equilibration period, four urine collections of approximately $10 \mathrm{~min}$ each were obtained. Blood was drawn in the middle of each period. The dogs then received $0.85 \mathrm{~g} / \mathrm{dl} \mathrm{NaCl}, 75 \mathrm{ml} / \mathrm{kg}$, infused over $15 \mathrm{~min}$. Three additional $10-\mathrm{min}$ urine collections were then obtained.

$T m_{P A H}$. A tap water load of $50 \mathrm{ml} / \mathrm{kg}$ was given by nasogastric tube, and $40 \mathrm{ml} / \mathrm{kg} 0.45 \mathrm{~g} / \mathrm{dl} \mathrm{NaCl}$ was infused intravenously over $20 \mathrm{~min}$ to hydrate the dogs. Priming doses of PAH and creatinine similar to the first protocol were given. A sustaining solution of $0.45 \mathrm{~g} / \mathrm{dl} \mathrm{NaCl}$ containing creatinine and $\mathrm{PAH}$ was administered at $0.5 \mathrm{ml} / \mathrm{kg}$ per min. After a 45-min equilibration period, four 10-min collections of urine were obtained with blood drawn midway through each collection period. A bolus of $20 \mathrm{~g} / \mathrm{dl} \mathrm{PAH}$ calculated to raise the serum $\mathrm{PAH}$ concentration to 30-40 $\mathrm{mg} / \mathrm{dl}$ was then administered and additional $\mathrm{PAH}$ added to the sustaining solution to maintain it in this range. After $30 \mathrm{~min}$, four additional 10-min urine collections were obtained.

Four group III dogs had chronically implanted polyvinylchloride catheters $(1.37 \mathrm{~mm}$ OD, $0.64 \mathrm{~mm}$ ID) in the aorta for monitoring blood pressure. Pressure was measured utilizing a Statham P23Db strain gauge (Statham Instruments, Oxnard, Calif.) and a multichannel recorder (Gilson Medical Electronics, Inc., Middleton, Wis.). The strain gauge was positioned at the upper level of the base of the tail.

The clearance of exogenous creatinine was used as an index of the GFR; $C_{P A H}$ was used as an approximation of the renal plasma flow. Maximum urine osmolality ( $U_{\max }$ ) was determined on urine collected after $16-18 \mathrm{~h}$ of water deprivation. Standard formulas were used for the calculation of creatinine, PAH, osmolal, and free water clearances, filtration fraction, and fractional excretion of sodium and water.

Analytical methods. Serum and urine creatinine and $\mathrm{PAH}$ concentrations were obtained on an AutoAnalyzer (Technicon Instruments Corp., Tarrytown, N. Y.) ; osmolality was determined by freezing point depression (Advanced Instruments, Inc., Needham Heights, Mass.); specimens for $\mathrm{Na}$ and $\mathrm{K}$ were analyzed on a flame photometer (Instrumentation Laboratory. Inc., Lexington, Mass.).

Statistical methods. Standard error of mean is used as an index of dispersion. Significance was ascertained using Student's $t$ test for paired samples.

Kidney biopsy tissue was studied by light and immunofluorescent microscopic techniques. 2- $\mu \mathrm{m}$ sections of the paraffin-embedded tissue were stained with hematoxylin and eosin and periodic acid-Schiff reaction. Frozen tissue sections were stained with commercially prepared fluorescein isothiocyanate-labeled antisera (Cappel Laboratories, Downingtown, $\mathrm{Pa}$.) against sheep and $\operatorname{dog} \gamma$-globulin and against dog complement and examined by standard immunofluorescence techniques.

\section{RESULTS}

\section{Group I. Unilateral APGN, nonaccelerated}

Functional studies performed on six dogs with acute unilateral nephrotoxic nephritis before and immediately after an acute saline load are presented in Table I. Mean time of study after nephrotoxic serum injection was 6.2 days. By this time mean GFR in the injected kidneys had decreased to $31 \mathrm{ml} / \mathrm{min}$ compared to the intact kidney GFR of $50 \mathrm{ml} / \mathrm{min}$. CPAB was similar for both kidneys; consequently the filtration fraction for the APGN kidney, $24 \%$, was significantly lower than for the intact kidney, $40 \%, P<0.005$. Urinary sodium excretion and $\mathrm{FE}_{\mathrm{Na}}$ were markedly lower from the APGN kidney than intact kidney in each of the six dogs, 8.6 vs. $51.1 \mu \mathrm{eq} /$ $\min$ and 0.20 vs. $0.75 \%$, respectively, $P<0.005$. The fractional excretion of water and free water clearance/ GFR were not significantly different for the two kidneys while the osmolal clearance/GFR for the APGN kidney at $3.3 \%$ was less than the $4.1 \%$ for the intact kidney, $P<0.05$. Maximum concentrating ability was decreased for the APGN kidney, $1,145 \mathrm{mosmol} / \mathrm{kg}$, but normal for the intact kidney, $1,789 \mathrm{mosmol} / \mathrm{kg}, P<0.01$.

After acute isotonic saline volume expansion, the GFR in the APGN kidney and intact kidney increased 4 and $12 \%$, respectively, $P>0.05$. However, mean $\mathrm{C}_{\mathbf{P A H}}$ increased significantly less for the APGN kidney, $11 \%$, than for the intact kidney, $44 \%, P<0.05$. Of particular note was that volume expansion exaggerated the baseline difference in $\mathrm{FE}_{\mathrm{Na}}$ for the two kidneys. The absolute increase in $\mathrm{FE}_{\mathrm{Na}}$ of $1.6 \%$ for the APGN kidney was significantly less than the $4.0 \%$ from the intact kidney, $P<0.01$.

Table II presents the results of $T_{\mathrm{PAB}}$ studies on three of the foregoing six dogs. Although variable, mean tubular secretion of $\mathrm{PAH}$ after $\mathrm{PAH}$ loading was similar for both kidneys, 4.2 and $4.6 \mathrm{mg} / \mathrm{min}$. Thus, when factored by GFR, the TmPAB/GFR was greater for the APGN kidney than intact kidney for each dog, the mean being $13.1 \mathrm{mg} / \mathrm{dl}$ for the APGN kidneys and $9.3 \mathrm{mg} / \mathrm{dl}$ for the intact kidneys.

Sequential studies were performed on three of the original six dogs in which the externally draining cystostomy tubes did not become obstructed. Each of these dogs at times ranging from 14 to 59 days reversed their sodium excretion patterns in response to extracellular fluid volume expansion. The results of the initial "early" study and study at the time of reversal, designated "late" study, are presented in Table III." Two of the three

${ }^{3}$ Data for the chronic studies on dogs 57 and 75 have previously been reported $(10)$. 
TABLE I

Base-line Functional Data for Group I Dogs with Unilateral Nonaccelerated

\begin{tabular}{|c|c|c|c|c|c|c|c|c|c|}
\hline \multirow[b]{2}{*}{ Dog } & \multirow[b]{2}{*}{ Day* } & \multicolumn{2}{|c|}{ GFR } & \multicolumn{2}{|c|}{ CPAH } & \multicolumn{2}{|c|}{ FF } & \multicolumn{2}{|c|}{$\mathrm{UNa}_{\mathrm{Na}}$} \\
\hline & & APGN & IK & APGN & IK & APGN & IK & APGN & IK \\
\hline & & \multicolumn{2}{|c|}{$\operatorname{ml} / \min$} & \multicolumn{2}{|c|}{$m l / m i n$} & \multicolumn{2}{|c|}{$\%$} & \multicolumn{2}{|c|}{$\mu e q / \min$} \\
\hline \multicolumn{10}{|c|}{ Base-line functional data } \\
\hline 57 & 7 & 32 & 53 & 128 & 101 & 25 & 52 & 6.1 & 59.7 \\
\hline 75 & 13 & 19 & 44 & 108 & 97 & 18 & 46 & 1.4 & 58.6 \\
\hline 77 & 5 & 37 & 41 & 125 & 71 & 30 & 45 & 13.5 & 54.0 \\
\hline 78 & 6 & 31 & 55 & 174 & 232 & 18 & 24 & 14.3 & 57.4 \\
\hline 110 & 3 & 29 & 62 & 110 & 162 & 27 & 39 & 13.0 & 38.9 \\
\hline 114 & 3 & 40 & 46 & 162 & 129 & 25 & 36 & 3.1 & 37.9 \\
\hline Mean & 6.2 & 31 & 50 & 135 & 132 & 24 & 40 & 8.6 & 51.1 \\
\hline SEM & & 3 & 3 & 11 & 24 & 2 & 4 & 2.3 & 4.1 \\
\hline$P$ & & \multicolumn{2}{|c|}{$<0.005$} & \multicolumn{2}{|c|}{$>0.4$} & \multicolumn{2}{|c|}{$<0.005$} & \multicolumn{2}{|c|}{$<0.005$} \\
\hline
\end{tabular}

Results after acute isotonic saline volume expansion

\begin{tabular}{|c|c|c|c|c|c|c|c|c|}
\hline Mean & 33 & 56 & 148 & 173 & 22 & 33 & 83.8 & 373 \\
\hline SEM & 4 & 3 & 16 & 16 & 1 & 2 & 24 & 80 \\
\hline$\% \Delta \ddagger$ & 4 & 12 & 11 & 44 & & & & \\
\hline Absolute $\Delta \S$ & \multirow{2}{*}{\multicolumn{2}{|c|}{$>0.05$}} & \multirow{2}{*}{\multicolumn{2}{|c|}{$<0.05$}} & -1 & -7 & 75.3 & 322 \\
\hline$P$ & & & & & & & \multicolumn{2}{|c|}{$<0.01$} \\
\hline
\end{tabular}

The following abbreviations are used: $\mathrm{FF}$, filtration fraction; $\mathrm{U}_{\mathrm{Na}} \mathrm{V}$, excretion rate of sodium; $\mathrm{FE}_{\mathrm{Na}}$, fractional excretion of sodium; $\mathrm{FE}_{\mathrm{H}_{2} \mathrm{O}}$, fractional excretion of water; $\mathrm{C}_{\mathrm{osm}}$, osmolal clearance; $\mathrm{C}_{\mathrm{H}_{2} \mathrm{O}}$, free water clearance; $U_{\max }$, maximum urine osmolality; IK, intact kidney.

* Number of days after disease induction.

$\ddagger$ Percent change (after expansion minus base line/base line $\times 100$ ).

$\$$ Results after expansion minus base line.

TABLE II

Maximum Tubular Secretion of PAH $\left(T m_{P A H}\right)^{*}$

\begin{tabular}{|c|c|c|c|c|c|c|c|c|c|c|c|c|c|}
\hline \multirow[b]{3}{*}{ Dog } & \multirow[b]{3}{*}{ Day } & \multicolumn{8}{|c|}{ Base-line } & \multicolumn{4}{|c|}{ After PAH load } \\
\hline & & \multicolumn{2}{|c|}{ GFR } & \multicolumn{2}{|c|}{ СPAH } & \multicolumn{2}{|c|}{ FF } & \multicolumn{2}{|c|}{$\mathrm{FE}_{\mathrm{Na}}$} & \multicolumn{2}{|c|}{ TmPAH } & \multicolumn{2}{|c|}{ TmPAH/GFR } \\
\hline & & APGN & IK & APGN & IK & APGN & IK & APGN & IK & APGN & IK & APGN & IK \\
\hline & & \multicolumn{2}{|c|}{$m l / m i n$} & \multicolumn{2}{|c|}{$\mathrm{ml} / \mathrm{min}$} & \multicolumn{2}{|c|}{$\%$} & \multicolumn{2}{|c|}{$\%$} & \multicolumn{2}{|c|}{$m g / m i n$} & \multicolumn{2}{|c|}{$m g / d l$} \\
\hline \multicolumn{14}{|c|}{ Three dogs from group I with nonaccelerated unilateral APGN } \\
\hline 57 & 8 & 32 & 57 & 159 & 147 & 20 & 39 & 0.17 & 0.91 & 3.6 & 4.0 & 11.7 & 8.2 \\
\hline 75 & 7 & 25 & 48 & 106 & 114 & 24 & 42 & 0.19 & 0.78 & 3.1 & 4.8 & 15.1 & 11.7 \\
\hline 114 & 2 & 54 & 63 & 234 & 191 & 25 & 36 & 0.22 & 0.64 & 6.1 & 4.9 & 12.6 & 8.1 \\
\hline Mean & & 37 & 56 & 186 & 151 & 23 & 39 & 0.19 & 0.78 & 4.2 & 4.6 & 13.1 & 9.3 \\
\hline \multicolumn{14}{|c|}{ Four dogs from group II with accelerated unilateral APGN } \\
\hline 18 & 8 & 10 & 66 & 31 & 209 & 32 & 31 & 1.76 & 0.69 & 1.6 & 11.2 & 22.7 & 24.4 \\
\hline 20 & 7 & 7 & 76 & 19 & 176 & 37 & 43 & 1.64 & 0.53 & 7.9 & 9.1 & 13.5 & 13.5 \\
\hline 31 & 8 & 33 & 52 & 130 & 174 & 25 & 30 & 0.85 & 0.79 & 8.6 & 13.0 & 28.3 & 29.6 \\
\hline 160 & 6 & 26 & 61 & 104 & 260 & 25 & 24 & 0.64 & 0.04 & 1.5 & 3.7 & 7.2 & 6.4 \\
\hline Mean & & 19 & 64 & 71 & 205 & 30 & 32 & 1.22 & 0.51 & 4.9 & 9.2 & 17.9 & 18.5 \\
\hline
\end{tabular}

* Abbreviations are the same as in Table I. 
APGN and Results after Acute Isotonic Saline Volume Expansion

\begin{tabular}{|c|c|c|c|c|c|c|c|c|c|}
\hline \multicolumn{2}{|c|}{$\mathrm{FE}_{\mathrm{Na}}$} & \multicolumn{2}{|c|}{$\mathrm{FE}_{\mathrm{H}_{2} \mathrm{O}}$} & \multicolumn{2}{|c|}{ Cosm/GFR } & \multicolumn{2}{|c|}{$\mathrm{C}_{\mathrm{H}_{2} \mathrm{O} / \mathrm{GFR}}$} & \multicolumn{2}{|c|}{$\mathrm{U}_{\max }$} \\
\hline APGN & IK & APGN & IK & APGN & IK & APGN & IK & APGN & IK \\
\hline \multicolumn{2}{|c|}{$\%$} & \multicolumn{2}{|c|}{$\%$} & \multicolumn{2}{|c|}{$\%$} & \multicolumn{2}{|c|}{$\%$} & \multicolumn{2}{|c|}{ mosmol/kg } \\
\hline 0.14 & 0.81 & 1.7 & 1.8 & 3.6 & 4.5 & -2.0 & -2.8 & 1,528 & 2,381 \\
\hline 0.05 & 0.94 & 1.3 & 2.2 & 3.2 & 5.4 & -1.9 & -3.3 & 1,546 & 1,680 \\
\hline 0.26 & 0.93 & 2.1 & 3.0 & 2.9 & 3.7 & -0.9 & -0.9 & 350 & 1,518 \\
\hline 0.33 & 0.76 & 3.2 & 4.2 & 3.8 & 4.5 & -0.8 & -0.6 & 596 & 1,432 \\
\hline 0.34 & 0.48 & 3.2 & 2.5 & 3.4 & 3.5 & -0.4 & -1.2 & 475 & 1,236 \\
\hline 0.05 & 0.56 & 1.8 & 2.1 & 2.8 & 3.2 & -1.1 & -1.2 & 2,372 & 2,484 \\
\hline 0.20 & 0.75 & 2.2 & 2.6 & 3.3 & 4.1 & -1.2 & -1.7 & 1,145 & 1,789 \\
\hline 0.05 & 0.08 & 0.3 & 0.4 & 0.2 & 0.3 & 0.3 & 0.5 & 326 & 212 \\
\hline \multicolumn{2}{|c|}{$<0.005$} & \multicolumn{2}{|c|}{$>0.05$} & \multicolumn{2}{|c|}{$<0.05$} & \multicolumn{2}{|c|}{$>0.05$} & \multicolumn{2}{|c|}{$<0.01$} \\
\hline 1.8 & 4.8 & 9.1 & 11.9 & 5.2 & 8.2 & 3.2 & 2.8 & & \\
\hline 0.4 & 0.9 & 1.6 & 1.1 & 0.4 & 0.8 & 1.3 & 0.9 & & \\
\hline 1.6 & 4.0 & 6.8 & 9.2 & 1.9 & 4.1 & 4.4 & 4.4 & & \\
\hline \multicolumn{2}{|c|}{$<0.01$} & \multicolumn{2}{|c|}{$<0.05$} & \multicolumn{2}{|c|}{$<0.05$} & \multicolumn{2}{|c|}{$>0.4$} & & \\
\hline
\end{tabular}

dogs had a moderate-to-marked decrease in APGN kidney GFR between the time of the two studies, while the third had a slight increase. The GFRs of the intact kidney for both studies were relatively similar. The base-line $\mathrm{FE}_{\mathrm{Na}}$ was lower for the APGN kidney than intact kidney in each of the early studies but higher in two of three dogs at the time of the late study. However, the absolute increase in $\mathrm{FE}_{\mathrm{Na}}$ after isotonic saline volume expansion for each of the three dogs was now greater for the APGN kidney than intact kidney in the late study, whereas in the early study it was less. T⿸厂 for $\operatorname{dog} 75$, initially higher for the APGN kidney than intact kidney (Table II), became similar for both the APGN kidney and intact kidney, 12.1 vs. $12.3 \mathrm{mg} / \mathrm{dl}$, respectively.

TABLE III

Functional Data on Three Group I Dogs with Unilateral APGN for Early and Late Studies before/after Acute Isotonic Saline Volume Expansion*

\begin{tabular}{|c|c|c|c|c|c|c|c|c|}
\hline \multirow[b]{2}{*}{ Dog } & & \multirow[b]{2}{*}{ Day } & \multicolumn{2}{|c|}{ GFR } & \multicolumn{2}{|c|}{$\mathrm{C}_{\mathrm{PAH}}$} & \multicolumn{2}{|c|}{$\mathrm{FE}_{\mathrm{Na}}$} \\
\hline & & & APGN & IK & APGN & IK & APGN & IK \\
\hline & & & \multicolumn{2}{|c|}{$m l / m i n$} & \multicolumn{2}{|c|}{$m l / m i n$} & \multicolumn{2}{|c|}{$\%$} \\
\hline 57 & $\begin{array}{l}\text { Early } \\
\text { Late }\end{array}$ & $\begin{array}{r}7 \\
14\end{array}$ & $\begin{array}{l}32 / 36 \\
10 / 11\end{array}$ & $\begin{array}{l}53 / 56 \\
57 / 49\end{array}$ & $\begin{array}{c}128 / 177 \\
56 / 67\end{array}$ & $\begin{array}{l}101 / 193 \\
138 / 187\end{array}$ & $\begin{array}{l}0.1 / 0.9 \\
0.5 / 5.0\end{array}$ & $\begin{array}{l}0.8 / 3.4 \\
1.1 / 3.2\end{array}$ \\
\hline 75 & $\begin{array}{l}\text { Early } \\
\text { Late }\end{array}$ & $\begin{array}{l}13 \\
49\end{array}$ & $\begin{array}{l}19 / 19 \\
22 / 25\end{array}$ & $\begin{array}{l}44 / 50 \\
52 / 52\end{array}$ & $\begin{array}{l}108 / 98 \\
101 / 111\end{array}$ & $\begin{array}{r}97 / 135 \\
141 / 184\end{array}$ & $\begin{array}{l}0.1 / 1.3 \\
0.6 / 5.9\end{array}$ & $\begin{array}{l}0.9 / 4.8 \\
0.3 / 4.4\end{array}$ \\
\hline 110 & $\begin{array}{l}\text { Early } \\
\text { Late }\end{array}$ & $\begin{array}{r}3 \\
59\end{array}$ & $\begin{array}{c}29 / 31 \\
1.4 / 1.9\end{array}$ & $\begin{array}{l}62 / 67 \\
50 / 53\end{array}$ & $\begin{array}{c}110 / 128 \\
7 / 8\end{array}$ & $\begin{array}{l}162 / 228 \\
227 / 247\end{array}$ & $\begin{array}{l}0.3 / 3.5 \\
1.2 / 5.2\end{array}$ & $\begin{array}{l}0.5 / 5.0 \\
0.1 / 2.7\end{array}$ \\
\hline
\end{tabular}

* Abbreviations are the same as in Table I. 
TABLE IV

Base-line Functional Data for Group II Dogs with Unilateral Accelerated

\begin{tabular}{|c|c|c|c|c|c|c|c|c|c|}
\hline \multirow[b]{2}{*}{ Dog } & \multirow[b]{2}{*}{ Day } & \multicolumn{2}{|c|}{ GFR } & \multicolumn{2}{|c|}{ CPAH } & \multicolumn{2}{|c|}{ FF } & \multicolumn{2}{|c|}{$\mathrm{U}_{\mathrm{Na}} \mathrm{V}$} \\
\hline & & APGN & IK & APGN & IK & APGN & IK & APGN & IK \\
\hline & & \multicolumn{2}{|c|}{$\mathrm{ml} / \mathrm{min}$} & \multicolumn{2}{|c|}{$\mathrm{ml} / \mathrm{min}$} & \multicolumn{2}{|c|}{$\%$} & \multicolumn{2}{|c|}{$\mu e q / \min$} \\
\hline \multicolumn{10}{|c|}{ Base-line functional data } \\
\hline 18 & 7 & 6 & 44 & 29 & 180 & 22 & 24 & 1.7 & 1.1 \\
\hline 20 & 4 & 4 & 60 & 18 & 216 & 24 & 28 & 1.2 & 1.3 \\
\hline 30 & 5 & 33 & 85 & 115 & 258 & 28 & 33 & 15.6 & 33.7 \\
\hline 31 & 8 & 22 & 33 & 100 & 131 & 22 & 25 & 2.3 & 2.5 \\
\hline 46 & 4 & 14 & 60 & 58 & 176 & 25 & 35 & 7.9 & 3.7 \\
\hline 160 & 4 & 17 & 59 & 54 & 153 & 32 & 38 & 1.8 & 21.5 \\
\hline Mean & 5.3 & 16 & 57 & 62 & 186 & 25 & 31 & 5.1 & 10.6 \\
\hline SEM & & 4 & 7 & 16 & 19 & 2 & 2 & 2.3 & 5.6 \\
\hline$P$ & & \multicolumn{2}{|c|}{$<0.005$} & \multicolumn{2}{|c|}{$<0.005$} & \multicolumn{2}{|c|}{$<0.005$} & \multicolumn{2}{|c|}{$>0.1$} \\
\hline \multicolumn{10}{|c|}{ Results after isotonic saline volume expansion } \\
\hline Mean & & 20 & 62 & 75 & 230 & 27 & 27 & 186 & 258 \\
\hline SEM & & 5 & 7 & 18 & 26 & 0.7 & 0.8 & 63 & 57 \\
\hline$\% \Delta$ & & 29 & 11 & 21 & 26 & & & & \\
\hline Absolute $\Delta$ & & \multirow{2}{*}{\multicolumn{2}{|c|}{$>0.05$}} & & & 2 & -4 & 180 & 248 \\
\hline$P$ & & & & \multicolumn{2}{|c|}{$>0.1$} & \multicolumn{2}{|c|}{$<0.05$} & \multicolumn{2}{|c|}{$>0.1$} \\
\hline
\end{tabular}

* Abbreviations are the same as in Table $\mathrm{I}$.

\section{Group II. Unilateral APGN, accelerated}

Data for six dogs with accelerated unilateral APGN is presented in Table IV. Mean time of study was $\mathbf{5 . 3}$ days after nephrotoxic serum injection. By this time mean GFR in the APGN kidney had decreased to 16 $\mathrm{mi} / \mathrm{min}$ compared to $57 \mathrm{ml} / \mathrm{min}$ for the intact kidney. Mean C $_{\text {PAH }}$ was $62 \mathrm{ml} / \mathrm{min}$ for the kidney with APGN and $186 \mathrm{ml} / \mathrm{min}$ for the intact kidney with the resultant filtration fractions of 25 and $31 \%$ being significantly different, $P<0.005$. The $\mathrm{FE}_{\mathrm{Na}}$ was higher in five/six dogs in the APGN kidney than intact kidney, although the mean $\mathrm{FE}_{\mathrm{Na}}$ for the two kidneys of 0.22 and $0.12 \%$, respectively, was not statistically different, $P>0.1$. The urinary sodium excretion of $5.1 \mu \mathrm{eq} / \mathrm{min}$ for the APGN kidney and $10.6 \mu \mathrm{eq} / \mathrm{min}$ for the intact kidney also was not statistically different, $P>0.1$. The difference in fractional excretion of water and free water clearance/ GFR for the two kidneys was significant while the osmolal clearance/GFR was similar for both kidneys.

After acute isotonic saline expansion, the slightly greater increase in GFR and $\mathrm{C}_{\mathbf{P A}}$ in the APGN kidney did not achieve statistical significance compared to the intact kidney. The filtration fractions, however, changed in opposite directions, increasing in the APGN kidney and decreasing in the intact kidney, $P<0.05$. The absolute increase in $\mathrm{FE}_{\mathrm{Na}}$ in the APGN kidney of $5.8 \%$ was statistically greater than in the intact kidney of
$2.9 \%, P<0.05$. This is in contrast to group I dogs in which the increase in $\mathrm{FE}_{\mathrm{Na}}$ was less in the APGN kidney than intact kidney. Fig. 1 illustrates the difference between groups I and II in the sodium excretory pat-

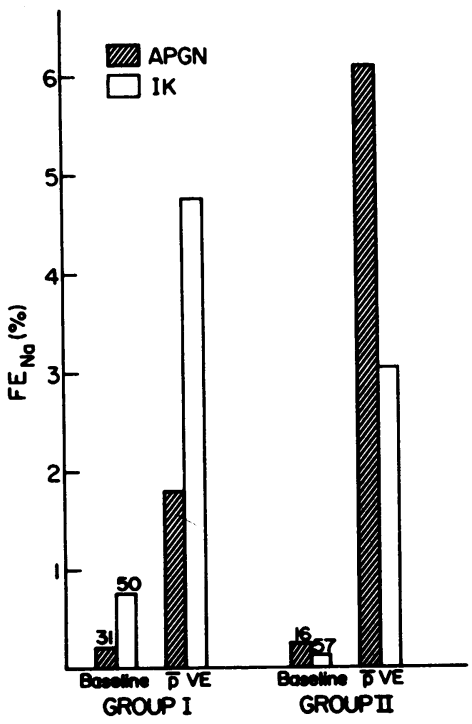

FIGURE 1 Comparison of the different patterns of sodium excretion for the APGN kidney and intact kidney (IK) for dogs in groups I and II before (base-line) and after ( $\bar{p}$ VE) volume expansion. Numbers above the bars indicate mean GFRs. 
APGN and Results after Acute Isotonic Saline Volume Expansion*

\begin{tabular}{|c|c|c|c|c|c|c|c|c|c|}
\hline \multicolumn{2}{|c|}{$\mathrm{FE}_{\mathrm{Na}}$} & \multicolumn{2}{|c|}{$\mathrm{FE}_{\mathrm{H}_{2} \mathrm{O}}$} & \multicolumn{2}{|c|}{ Cosm/GFR } & \multicolumn{2}{|c|}{$\mathrm{C}_{\mathrm{H}_{2} \mathrm{O} / \mathrm{GFR}}$} & \multicolumn{2}{|c|}{$\mathrm{U}_{\max }$} \\
\hline APGN & IK & APGN & IK & APGN & IK & APGN & IK & APGN & IK \\
\hline \multicolumn{2}{|c|}{$\%$} & \multicolumn{2}{|c|}{$\%$} & \multicolumn{2}{|c|}{$\%$} & \multicolumn{2}{|c|}{$\%$} & \multicolumn{2}{|c|}{$\mathrm{mosmol} / \mathrm{kg}$} \\
\hline 0.20 & 0.02 & 5.6 & 2.5 & 3.7 & 4.0 & 1.5 & -1.6 & 393 & 1,977 \\
\hline 0.22 & 0.02 & 3.2 & 1.8 & 4.9 & 5.0 & -1.9 & -3.3 & 684 & 2,169 \\
\hline 0.34 & 0.28 & 1.3 & 0.8 & 3.2 & 3.2 & -2.0 & -2.2 & 1,203 & 2,115 \\
\hline 0.07 & 0.05 & 2.2 & 1.8 & 一 & - & - & - & 1,443 & 1,824 \\
\hline 0.39 & 0.05 & 3.1 & 1.5 & 4.1 & 3.8 & -1.2 & -2.4 & 564 & 1,776 \\
\hline 0.08 & 0.27 & 2.7 & 2.9 & 3.8 & 4.3 & -1.3 & -1.6 & 914 & 1,330 \\
\hline 0.22 & 0.12 & 3.0 & 1.9 & 3.9 & 4.0 & -1.0 & -2.2 & 867 & 1,865 \\
\hline 0.05 & 0.05 & 0.6 & 0.3 & 0.3 & 0.3 & 0.6 & 0.3 & 163 & 124 \\
\hline \multicolumn{2}{|c|}{$>0.1$} & \multicolumn{2}{|c|}{$<0.05$} & \multicolumn{2}{|c|}{$>0.2$} & \multicolumn{2}{|c|}{$<0.05$} & \multicolumn{2}{|c|}{$<0.005$} \\
\hline 6.1 & 3.0 & 16.7 & 9.3 & 10.5 & 7.3 & 5.1 & 0.5 & & \\
\hline 1.3 & 0.5 & 2.2 & 1.6 & 1.4 & 0.7 & 1.9 & 1.4 & & \\
\hline 5.8 & 2.9 & 13.7 & 7.4 & 6.5 & 3.2 & 6.0 & 2.7 & & \\
\hline \multicolumn{2}{|c|}{$<0.05$} & \multicolumn{2}{|c|}{$<0.01$} & \multicolumn{2}{|c|}{$<0.05$} & \multicolumn{2}{|c|}{$<0.05$} & & \\
\hline
\end{tabular}

terns of the APGN and intact kidney before and after volume expansion.

TmPar studies undertaken on four of the foregoing six dogs are also presented in Table II. TMPAB was less for the APGN kidney than intact kidney, 4.9 vs. $9.2 \mathrm{mg} / \mathrm{min}$, respectively. However, when factored by GFR, the $\mathrm{Tm}_{\mathrm{PAH}} / \mathrm{GFR}$ was similar for both kidneys at $17.9 \mathrm{mg} / \mathrm{dl}$ for the APGN kidney and $18.5 \mathrm{mg} / \mathrm{dl}$ for the intact kidney. These results are in contrast to those in group I dogs (Table II).

\section{Group III. Bilateral APGN}

Sequential studies were performed on seven dogs after nephrotoxic serum injection with an initial control study obtained for comparison. The study for each dog which demonstrated the smallest (smallest natriuretic response) and largest (largest natriuretic response) absolute increase in $\mathrm{FE}_{\mathrm{Na}}$ after isotonic saline volume expansion was selected and compiled (Table V). In all seven dogs,

TABLE V

Group III Bilateral APGN. Base-Line and Post-Acute Isotonic Saline Volume Expansion Data on Seven Dogs (mean \pm SEM) at Three Periods during Progression of Nonaccelerated AGPN: Control, Smallest, and Largest Absolute Increase in $F E_{N a}$ (Natriuretic Response $[N R]$ ) after Volume Expansion*

\begin{tabular}{|c|c|c|c|c|c|c|c|c|c|c|}
\hline & Day & GFR & CPAH & FF & $\mathrm{U}_{\mathrm{Na}} \mathrm{V}$ & $\mathrm{FE}_{\mathrm{Na}}$ & $\mathrm{FE}_{2} \mathrm{O}$ & $\mathrm{BP} \ddagger$ & $\mathrm{U}_{\max }$ & Weight \\
\hline & & $\mathrm{ml} / \mathrm{min}$ & $\operatorname{ml} / \min$ & $\%$ & $\mu e q / \min$ & $\%$ & $\%$ & $m m H g$ & mosmol/kg & $k g$ \\
\hline \multicolumn{11}{|l|}{ Base-line } \\
\hline Control & $\mathbf{0}$ & $102 \pm 12$ & $266 \pm 23$ & $39 \pm 2$ & $48 \pm 13$ & $0.38 \pm 0.14$ & $2.3 \pm 0.6$ & $111 \pm 4$ & $1,737 \pm 173$ & $18.1 \pm 1.5$ \\
\hline Smallest NR & 3.1 & $65 \pm 8 \S$ & $280 \pm 36$ & $24 \pm 28$ & $15 \pm 68$ & $0.14 \pm 0.05$ & $1.9 \pm 0.4$ & $117 \pm 5$ & $1,009 \pm 181 \S$ & $18.1 \pm 1.4$ \\
\hline Largest NR & 10 & $25 \pm 6 \S$ & $152 \pm 44 \S$ & $22 \pm 5 \S$ & $17 \pm 4 \S$ & $0.71 \pm 0.20$ & $4.7 \pm 0.8$ & $122 \pm 78$ & $611 \pm 117 \S$ & $16.9 \pm 1.28$ \\
\hline \multicolumn{11}{|c|}{ Results after acute isotonic saline volume expansion } \\
\hline Control & & $108 \pm 12$ & $380 \pm 64 \|$ & $30 \pm 2 \|$ & $442 \pm 65 \|$ & $2.9 \pm 0.2 \|$ & $10.0 \pm 1.4 \|$ & $114 \pm 6$ & & \\
\hline Smallest NR & & $71 \pm 6 \|$ & $343 \pm 49 \|$ & $22 \pm 2 \| \S$ & $129 \pm 31 \|$ & $1.3 \pm 0.2 \| \S$ & $5.4 \pm 1.0 \| \S$ & $116 \pm 5$ & & \\
\hline Largest NR & & $28 \pm 7 \| \S$ & $163 \pm 46 \S$ & $26 \pm 6 \| 8$ & $193 \pm 54 \|$ & $5.6 \pm 1.2 \| \S$ & $14.1 \pm 1.3 \| 8$ & $121 \pm 6$ & & \\
\hline
\end{tabular}

* Abbreviations are the same as in Table I.

$\ddagger$ Blood pressure expressed as mean of four dogs.

$\$ P<0.05$ compared to either base-line control or after volume expansion control study.

$\| P<0.05$ compared to its paired base-line study. 


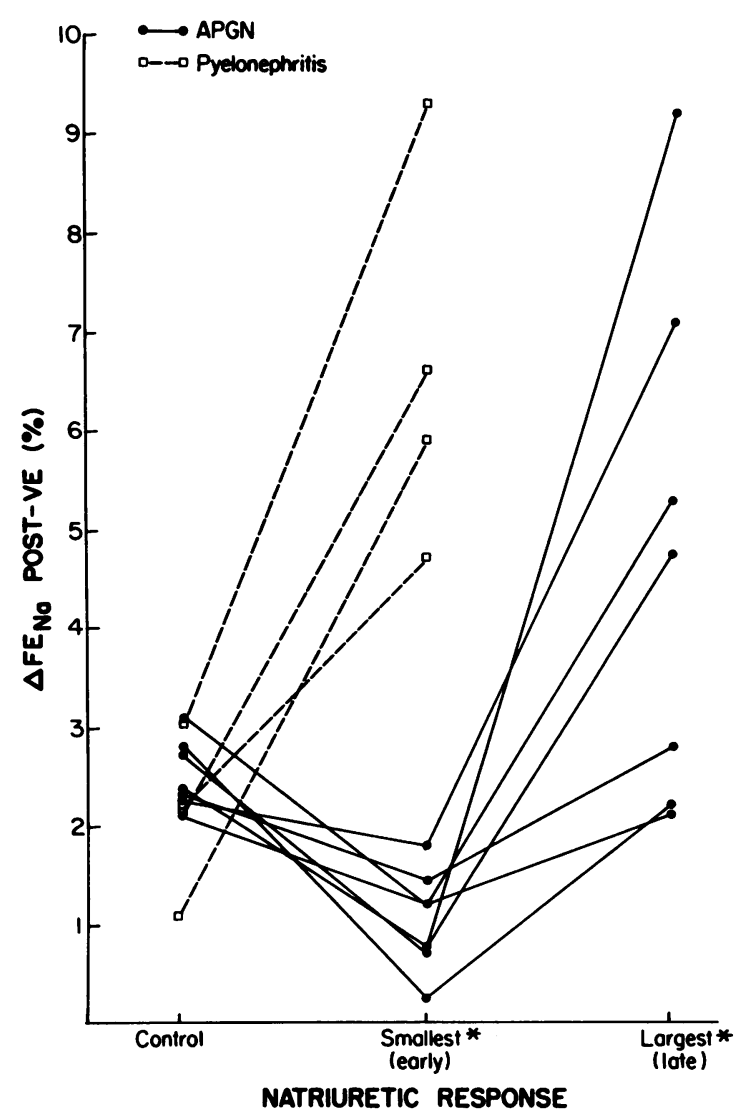

FIGURE 2 Bilateral APGN. Individual data on seven dogs for the absolute increase in $\mathrm{FE}_{\mathrm{Na}}$ (natriuretic response) after acute isotonic saline volume expansion at three periods during progression of their nonaccelerated nephrotoxic nephritis. The smallest natriuretic response occurred early in the course of nephrotoxic nephritis and in each instance before the largest natriuretic response. $(* P<0.05$ compared to control study). For comparison, individual data on dogs with acute bilateral pyelonephritis are also plotted. These dogs were studied at approximately the same time after disease induction as the bilateral APGN dogs when the latter animals demonstrated their smallest natriuretic response.

the smallest natriuretic response study occurred before the largest natriuretic response study.

Smallest natriuretic response. Mean time of study was 3.1 days after nephrotoxic serum injection, range 1 $h$ to 9 days. In all dogs the weight at the time of the smallest natriuretic response and control study was identical, mean weights for both studies being $18.1 \mathrm{~kg}$. Mean GFR of $65 \mathrm{ml} / \mathrm{min}$ was $69 \%$ (range 28 to $95 \%$ ) of the control mean GFR of $102 \mathrm{ml} / \mathrm{min}$. Although the mean $\mathrm{C}_{\mathbf{P A}}$ was higher after nephrotoxic serum at $280 \mathrm{ml} / \mathrm{min}$ compared to $266 \mathrm{ml} / \mathrm{min}$ for the control study, this difference was not significant, $P>0.3$. The filtration fraction was significantly lower at the time of the smallest natriuretic response study, $24 \%$, than for the control study, $39 \%, P<0.005$. Base-line control/smallest natriuretic response ratios for $\mathrm{FE}_{\mathrm{Na}}$ of $0.38 / 0.14 \%$, fractional excretion of water of $2.3 / 1.9 \%$, and mean blood pressure of $111 / 117 \mathrm{~mm} \mathrm{Hg}$ (recorded in four/seven dogs) were not significantly different. However, the difference in maximum urine osmolality of $1,737 / 1,009 \mathrm{mosmol} / \mathrm{kg}$ was significant, $P<0.05$. Acute extracellular fluid volume expansion resulted in a marked divergence in $\mathrm{FE}_{\mathrm{Na}}$. The absolute increase in $\mathrm{FE}_{\mathrm{Na}}$ of $2.5 \%$ during the control study was significantly greater than the $1.1 \%$ recorded during the smallest natriuretic response study, $P<0.005$ (Fig. 2). In no instance was the increase in urinary sodium excretion greater during the acute nephritis study than the control study.

Largest natriuretic response. Mean time after disease induction for these studies was 10 days (range 120 days). By this time the weight in five of seven dogs had decreased by 1-2 $\mathrm{kg}$. Mean GFR of $25 \mathrm{ml} / \mathrm{min}$ was $27 \%$ of the original GFR, range $4-70 \%$. C $_{\mathbf{A}}$ B had decreased to a mean of $152 \mathrm{ml} / \mathrm{min}, P<0.05$ compared to both the control and smallest natriuretic response studies. The filtration fraction was still depressed at $22 \%, P<$ 0.05 compared to the control study, but was not significantly different from the smallest natriuretic response study. Base-line $\mathrm{FE}_{\mathrm{Na}}$ of $0.71 \%$ was significantly greater than the $0.14 \%$ during the smallest natriuretic response study, $P<0.05$, but not significantly greater than the control study of $0.38 \%, P>0.1$. By this time the maximum urine osmolality had decreased to $611 \mathrm{mosmol} / \mathrm{kg}$ and mean blood pressure in the same four/seven dogs increased to $122 \mathrm{~mm} \mathrm{Hg}$, both significant at $P<0.01$. Isotonic saline volume expansion resulted in an absolute increase in $\mathrm{FE}_{\mathrm{Na}}$ of $4.9 \%$ in the largest natriuretic response studies, an increase significantly greater than both the smallest natriuretic response $(P<0.005)$ and control $(P<0.05)$ studies (Fig. 2). Volume expansion did not change the mean blood pressure significantly in any of the three studies.

For comparison with the bilateral APGN studies, acute bilateral pyelonephritis was induced in four dogs. The data for the control and acute pyelonephritis studies undertaken approximately 4 days after the induction procedure, the same interval after disease induction as the smallest natriuretic response study, are presented in Table VI. Each dog lost 1-2 kg by the time the acute pyelonephritis study was performed; thus it is likely all were volume contracted. Mean GFR was $95 \mathrm{ml} / \mathrm{min}$ before and $41 \mathrm{ml} / \mathrm{min}$ after pyelonephritis, but the severity of disease was quite variable with GFR reductions ranging from 12 to $67 \%$ of the original GFR. Although the mean urinary sodium excretion was similar before and after disease induction, 22.0 vs. $21.9 \mu \mathrm{eq} / \mathrm{min}$, there was marked individual variation. Base-line $F E_{\mathrm{Na}}$ was higher after pyelonephritis for three of four dogs with the overall mean being $0.17 \%$ before and $0.78 \%$ after pyelonephritis induction. The absolute increase in $\mathrm{FE}_{\mathrm{Na}}$ with extracellular fluid volume expansion during the control 
TABLE VI

Functional Data before $(C)$ and after Induction of Acute Pyelonephritis $(P)$ during Base-Line Conditions and after Acute Isotonic Saline Volume Expansion*

\begin{tabular}{|c|c|c|c|c|c|c|c|c|c|c|c|c|c|}
\hline \multirow[b]{2}{*}{ Dog } & \multirow[b]{2}{*}{ Day } & \multicolumn{2}{|c|}{ GFR } & \multicolumn{2}{|c|}{$\mathrm{C}_{\mathrm{PAH}}$} & \multicolumn{2}{|c|}{$\mathrm{UNaV}_{\mathrm{Na}}$} & \multicolumn{2}{|c|}{$\mathrm{FE}_{\mathrm{Na}}$} & \multicolumn{2}{|c|}{$U_{\max }$} & \multicolumn{2}{|c|}{ Weight } \\
\hline & & c & $\mathbf{P}$ & c & $\mathbf{P}$ & c & $\mathbf{P}$ & C & $\mathbf{P}$ & C & $\mathbf{P}$ & c & $\mathbf{P}$ \\
\hline & & \multicolumn{2}{|c|}{$m l / m i n$} & \multicolumn{2}{|c|}{$m l / m i n$} & \multicolumn{2}{|c|}{ meq/min } & \multicolumn{2}{|c|}{$\%$} & \multicolumn{2}{|c|}{ mosmol/kg } & \multicolumn{2}{|c|}{ kg } \\
\hline \multicolumn{14}{|l|}{ Base-line } \\
\hline 55 & 4 & 107 & 71 & 264 & 197 & 58.3 & 2.4 & 0.46 & 0.03 & 1,587 & 1,617 & 20.9 & 18.8 \\
\hline 65 & 4 & 62 & 17 & 151 & 52 & 6.3 & 32.6 & 0.07 & 1.42 & 1,365 & 429 & 17.7 & 16.0 \\
\hline 70 & 5 & 96 & 12 & 260 & 39 & 18.6 & 19.8 & 0.13 & 1.31 & 1,711 & 438 & 15.2 & 12.4 \\
\hline 72 & 4 & 116 & 63 & 293 & 171 & 4.9 & 32.9 & 0.03 & 0.37 & 1,173 & 520 & 18.6 & 17.4 \\
\hline Mean & & 95 & 41 & 242 & 115 & 22.0 & 21.9 & 0.17 & 0.78 & 1,459 & 751 & 18.1 & 16.2 \\
\hline SEM & & 12 & 15 & 31 & 40 & 12.5 & 7.2 & 0.10 & 0.34 & 119 & 289 & 1.2 & 1.4 \\
\hline \multicolumn{14}{|c|}{ Results after acute isotonic saline volume expansion } \\
\hline Mean & & 100 & 46 & 349 & 171 & 324 & 398 & 2.3 & 7.4 & & & & \\
\hline SEM & & 5 & 17 & 56 & 64 & 55 & 119 & 0.4 & 1.3 & & & & \\
\hline$\% \Delta$ & & 9 & 14 & 47 & 42 & & & & & & & & \\
\hline Absolute $\Delta$ & & & & & & 302 & 376 & 2.1 & 6.6 & & & & \\
\hline$P$ & & & & & & & & & 005 & & & & \\
\hline
\end{tabular}

* Abbreviations are the same as in Table I.

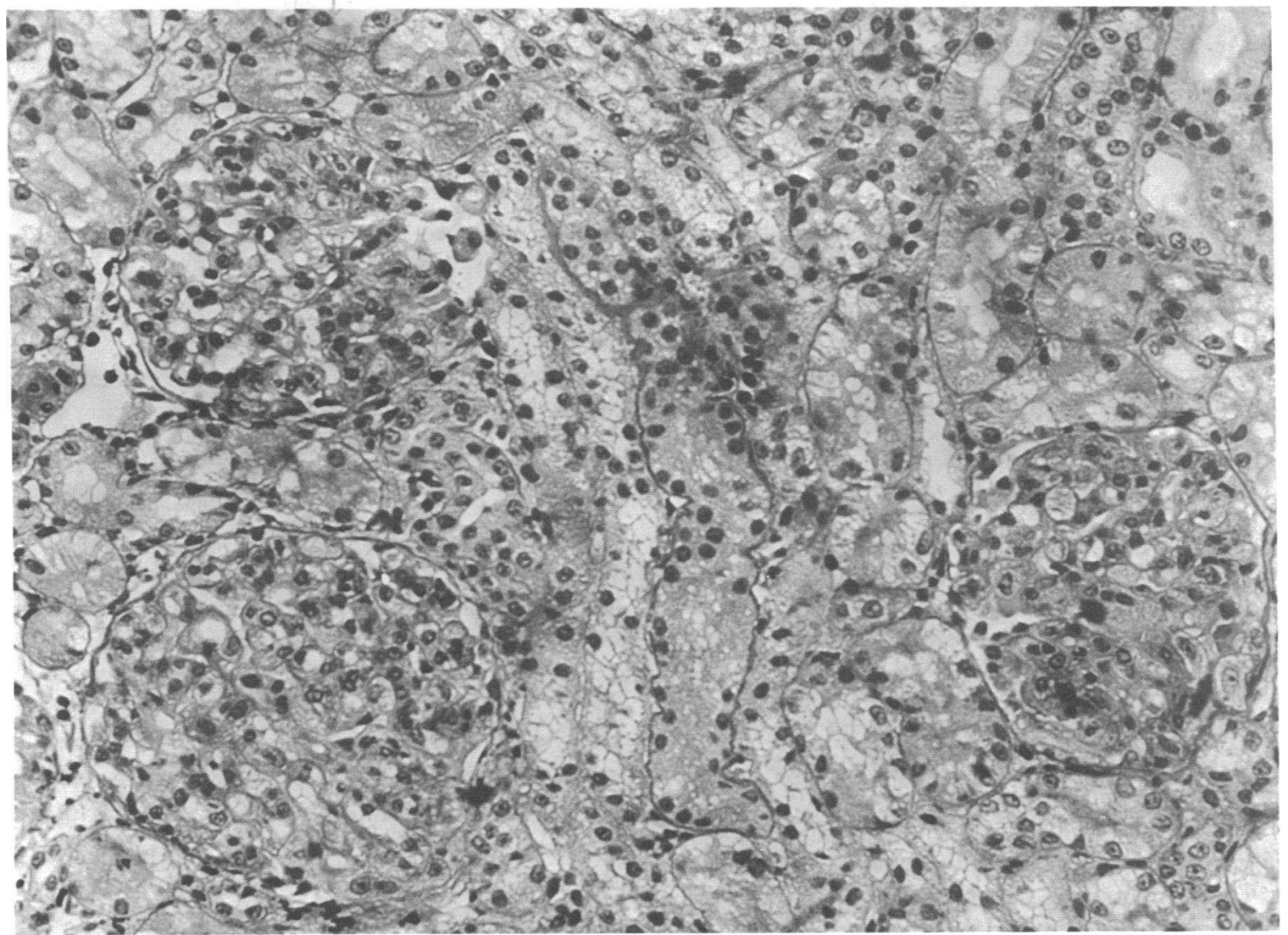

FIGURE 3 Biopsy from dog 57 APGN kidney at time of group I study. Glomeruli have increased cellularity, an influx of polymorphonuclear cells, swelling of endothelial and mesangial cell cytoplasm, and deposition of mesangial-matrix-like staining material in the mesangium. Tubule epithelial cells show hydropic swelling but otherwise are intact (X 235, periodic acidSchiff). 


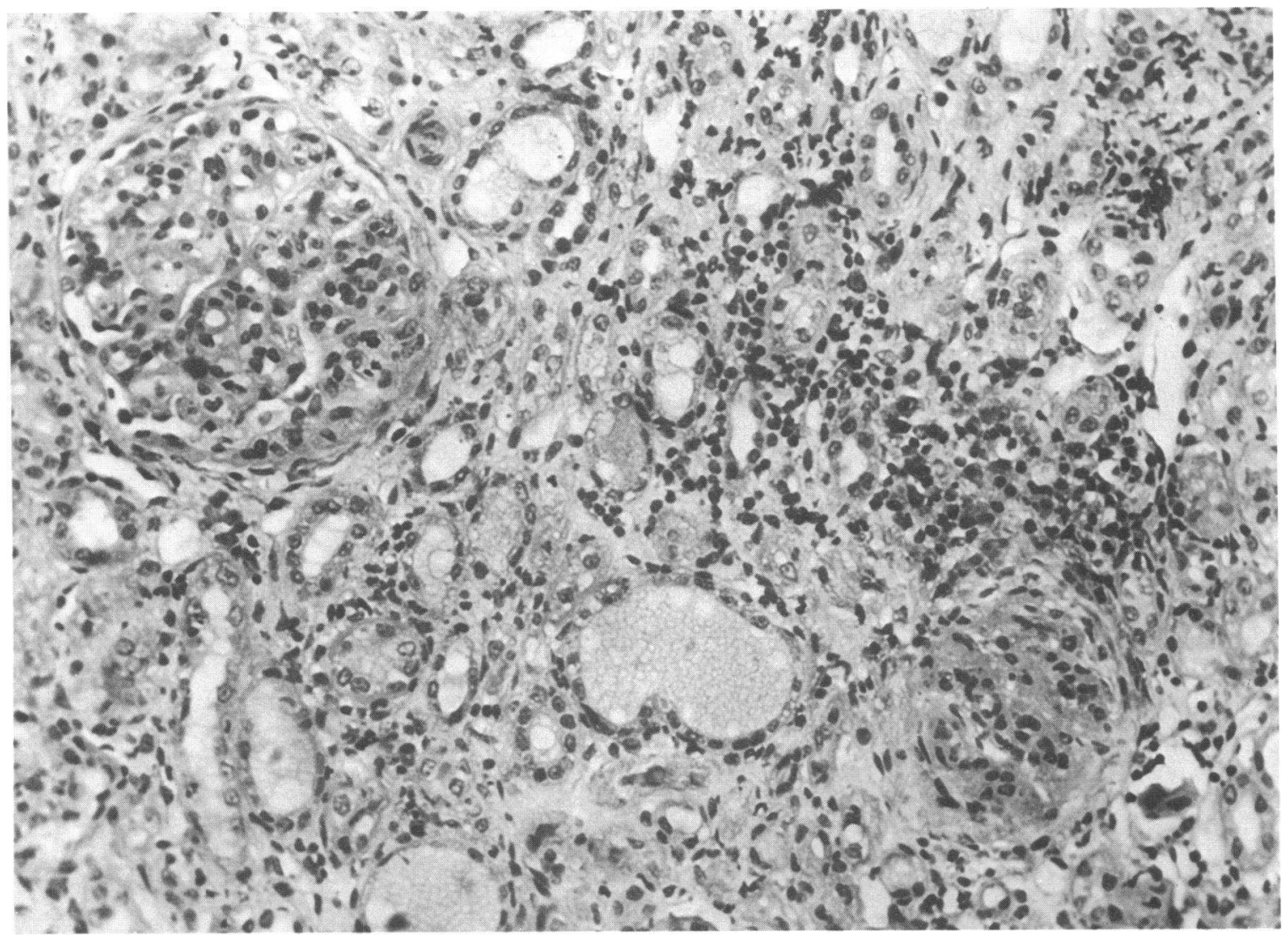

FIGURE 4 Biopsy from dog 57 APGN kidney at time of late study when the sodium excretion pattern was reversed compared to the early study. Marked tubular and interstitial damage is present along with changes of chronic glomerular injury (X 235, periodic acid-Schiff).

studies was $2.1 \%$; after pyelonephritis induction this increased to $6.6 \%, P<0.005$ (Fig. 2). In two dogs, 55 and 72 , despite lower GFRs, the absolute increase in urinary sodium excretion was greater after pyelonephritis.

\section{Histology}

Needle biopsies of the kidneys were obtained through flank incisions within 2 days of the time of the reported study on most dogs.

Immunofuorescence microscopy. The APGN kidneys in all three groups had the typical linear deposits of sheep and dog IgG. However, the intensity of sheep IgG was significantly less in group II APGN kidneys because of the smaller amount of nephrotoxic serum injected. Dog complement was present in an interrupted linear and diffuse granular pattern along capillary loops, and fibrinogen was occasionally present in Bowman's space. The intact kidneys in groups I and II were usually completely negative except for $\operatorname{dog}$ IgG which was present in varying intensity. Only rarely could a trace amount of sheep IgG and dog complement be detected. Tubules of APGN and intact kidneys in all groups were negative.
Light microscopy. The glomeruli in the APGN kidneys in group I had increased cellularity, an influx of polymorphonuclear cells, swelling of endothelial and mesangial cell cytoplasm, occasional thickening and splitting of the basement membrane and deposition of mesangial-matrix-like material in the mesangium. Hydropic swelling was present in many tubule epithelial cells and erythrocyte casts were abundant in tubule lumina. The interstitium rarely contained inflammatory cells (Fig. 3 ). The glomeruli in the intact kidney were normal with only an occasional glomerulus having a focal segmental increase in cellularity. The histologic changes in the APGN kidney at the time of the late study were primarily those of chronic disease. Many glomeruli had varying degrees of sclerosis and the remainder demonstrated increased cellularity. The most striking difference was in the interstitium which contained areas of tubular ablation or dilatation and foci of scarring and chronic inflammatory cell infiltration (Fig. 4). The APGN kidneys in group II had glomerular changes similar to group I but all contained significant interstitial damage. Interstitial edema was diffusely present along with interspersed areas of tubular destruction or 
dilatation and clusters of chronic inflammatory cells (Fig. 5). The intact kidney glomeruli in group II were nearly free of pathologic changes with only an occasional glomerulus showing increased cellularity. Histological alterations in group III dogs at the time of the smallest natriuretic response study were similar to the APGN kidney in group I (Fig. 6) while interstitial and tubular destruction, similar to that in the late group I and group II APGN kidneys, were present at the time of the largest natriuretic response study (Fig. 7).

\section{DISCUSSION}

Previous studies on functional adaptation of remaining nephrons in the diseased kidney have primarily involved chronic interstitial and, more recently, chronic glomerular disease $(6,10,15)$. The present studies focus on the adaptive response of nephrons in kidneys with acute immunologic glomerular injury. By studying dogs with unilateral Masugi's nephritis we were able to compare glomerulotubular balance in kidneys with acute proliferative glomerulonephritis of varying severity and contralateral intact kidneys in the nonuremic environment.

Group I and group II dogs were studied at the same time interval after disease induction. However, the functional and histologic changes were more severe in the APGN kidneys in group II because of presensitization of the dogs to sheep IgG, the animal source of the nephrotoxic antibody.

When studied early in the disease process, the functional characteristics of the APGN kidney in group I dogs corresponds to that seen in patients with a similar pathologic lesion. Similarities include an increase or only slight decrease in $\mathrm{C}_{\mathbf{P A B}}$ coupled with a variable decrease in GFR which results in a decreased filtration fraction. Furthermore, the $\mathrm{FE}_{\mathrm{Na}}$ from the APGN kidney was less than the contralateral intact kidney while maximum tubular secretion of PAH per GFR was higher for the APGN kidney than intact kidney. This corresponds to sodium and water retention and an increased $T_{m_{P A B}}$ / GFR in patients with APGN (1-4). The slight difference in base-line spdium excretion between the two

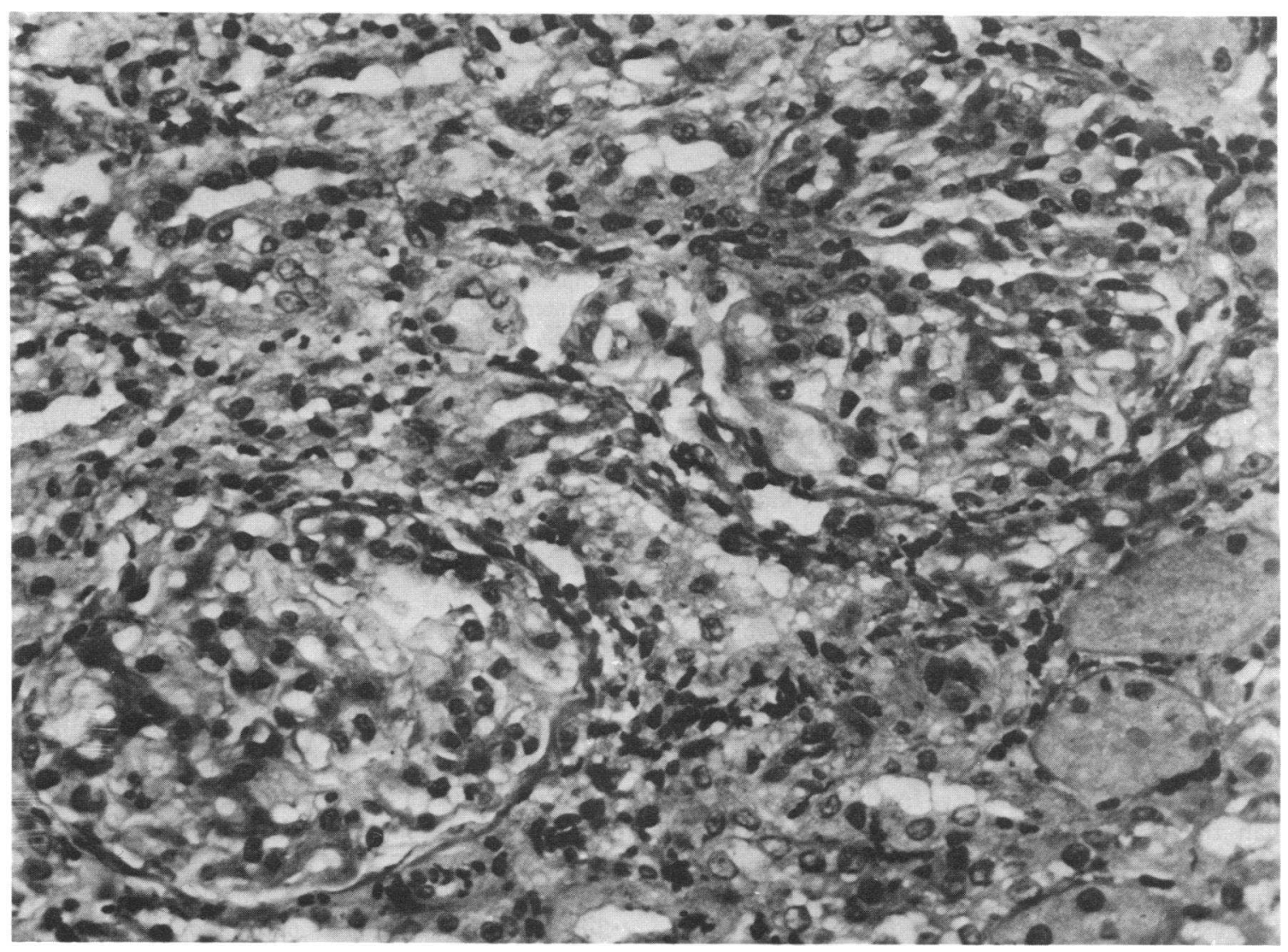

FIgURE 5 Biopsy from dog 46 APGN kidney at time of group II study. Glomeruli have a moderate increase in cellularity. Most tubules are in varying degrees of disintegration. Small foci of acute and chronic inflammatory cells are present in the interstitium (X 385 , periodic acid Schiff). 


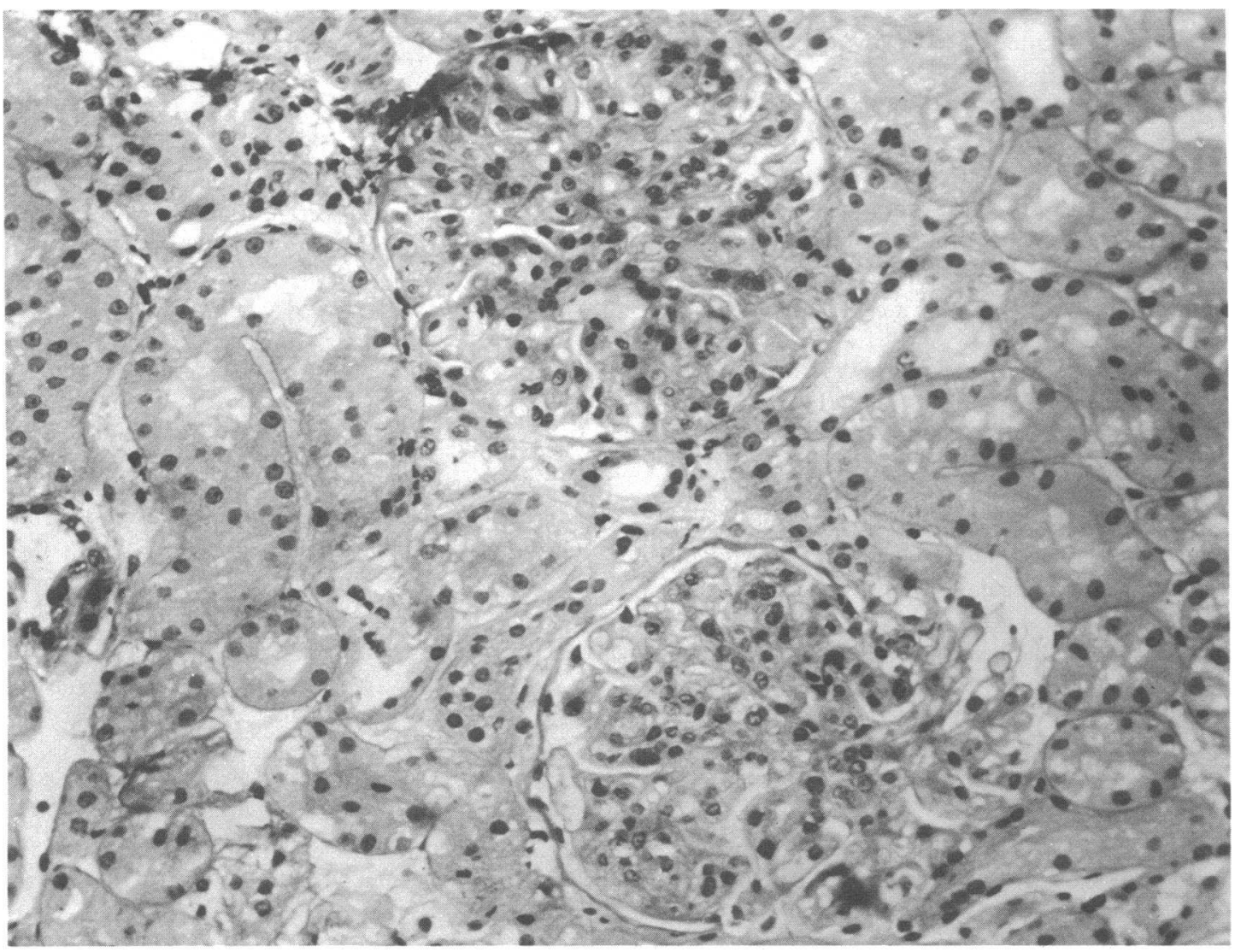

FIGURE 6 Biopsy from dog 58 with bilateral APGN at time of smallest natriuretic response study. Glomeruli show increased cellularity with cytoplasmic swelling, along with thickening and splitting of the basement membrane. Tubules and interstitium are relatively normal except for hydropic swelling of tubular epithelial cells (X 235, periodic acid-Schiff).

kidneys was exaggerated by extracellular fluid volume expansion. While the kidney with APGN was able to respond to an acute saline load, the absolute increase in $\mathrm{FE}_{\mathrm{Na}}$ was significantly less than for the intact kidney.

The functional pattern of the APGN kidney in the group II dogs exhibited marked differences compared to the APGN kidney group I dogs even though studied at the same time interval after nephrotoxic serum injection. Both the GFR and $C_{P A B}$ were lower than in group I, and the base-line $\mathrm{FE}_{\mathrm{Na}}$ was slightly, but not significantly, higher than the contralateral intact kidney. However, extracellular fluid volume expansion elicited a greater absolute increase in $\mathrm{FE}_{\mathrm{Na}}$ from the APGN kidney than the contralateral intact kidney, a result opposite to the group I studies. In addition, maximum tubular secretion of PAH per GFR was similar for both the APGN and intact kidney, also in contrast to the group I studies. These results for the group II studies are similar to those reported for the unilateral pyelonephritic and chronic glomerulonephritic dog models $(10,11,15,16)$.
Three of the original six group I dogs survived long enough for follow-up chronic studies. All exhibited a reversal of the APGN kidney/intact kidney sodium excretion pattern in response to extracellular volume expansion with the APGN kidney having a greater absolute increase in $\mathrm{FE}_{\mathrm{Na}}$ than the intact kidney. These results are similar to those seen in the group II studies. It is interesting to note that in dog 75 , despite a stable GFR in the diseased kidney, the sodium excretory pattern changed as the disease became chronic.

Sodium handling by the intact kidney in both models I and II was similar to the intact kidney in the dog model with a unilateral remnant or pyelonephritic kidney (11). Thus, it seems unlikely that a circulating antinatriuretic substance was responsible for decreased sodium excretion by the APGN kidney in group I.

The evolving functional pattern of sodium handling in dogs with bilateral nephrotoxic nephritis was similar to the APGN kidney in group I dogs. As compared to the prediseased state, there initially was sodium retention and a decreased natriuretic response to extracel- 
lular fluid volume expansion. As the disease progressed, the base-line $\mathrm{FE}_{\mathrm{Na}}$ increased (as would be necessary to maintain sodium homeostasis with a decreased GFR), and there was an exaggerated natriuretic response to extracellular volume expansion. These dogs were not on a fixed salt intake. However, at the time of the smallest absolute increase in sodium excretion in response to volume expansion, body weight had not changed significantly suggesting they were not volume contracted. Furthermore, comparison with dogs with bilateral pyelonephritis, studied at the same time interval after disease induction when all the latter animals had lost weight and presumably were volume contracted, showed that all the pyelonephritic dogs had an exaggerated natriuretic response to volume expansion compared to their base-line studies.

The severity of damage to the APGN kidney as reflected by the percent reduction in GFR would appear to predict the functional pattern of sodium excretion in most instances. In group I all APGN kidneys had a GFR greater than $40 \%$ of the intact kidney while in group II, five of the six APGN kidneys had a GFR less than $40 \%$ of the intact kidney. Similarly, with bilateral disease six of the seven in the smallest natriuretic response group had a GFR greater than $40 \%$ of the control study while in the largest natriuretic response study five of the seven had GFRs less than $40 \%$. In contrast, even with a mild reduction in GFR, the pyelonephritic kidneys demonstrated exaggerated natriuresis in response to volume expansion. Histologically the most prominent differences among the APGN kidneys in groups I and II were the presence of interstitial edema, inflammatory cell infiltrates, and evidence of tubular destruction in the group II APGN kidneys. Thus, the presence of interstitial or tubular damage may be a major determinant of the degree of natriuresis in response to volume expansion in addition to the absolute reduction in GFR.

Godon has recently reported that rats with mild chronic nephrotoxic nephritis have a decreased base-line $\mathrm{FE}_{\mathrm{Na}}$ and a decreased natriuretic response to volume expansion compared to control rats (9). The pathologic alterations in these kidneys were limited to the glomeruli, and thus his findings are compatible with our observa-

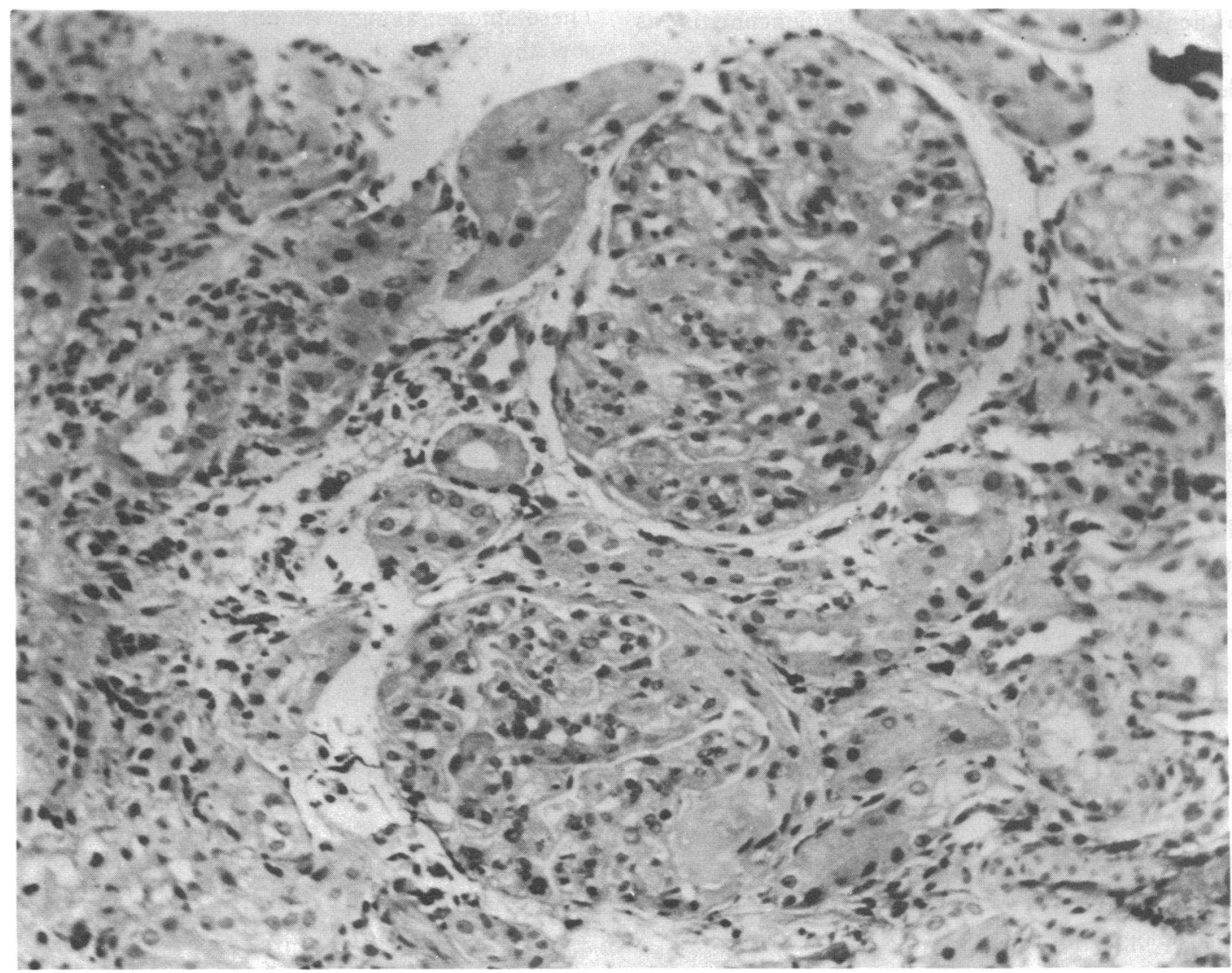

Figure 7 Biopsy from dog 50 with bilateral APGN at time of largest natriuretic response study. Glomeruli show increased cellularity, similar to that seen in Fig. 5, and thickening of capillary loops. There is extensive tubular and interstitial damage ( $\mathrm{X} 235$, periodic acid-Schiff). 
tions for the APGN kidney in group I and the smallest natriuretic response study in group III dogs with bilateral disease. Lubowitz et al. (6) and Allison et al. (8) found the $\mathrm{FE}_{\mathrm{Na}}$ in rats with moderate-to-severe nephrotoxic nephritis to be increased despite a decreased single nephron GFR. Histologic changes in these rats were more severe than those reported by Godon and included interstitial and tubular as well as glomerular damage. Thus their results are compatible with our findings for the APGN kidney in group II and in the largest natriuretic response study in group III dogs with bilateral disease.

The influence of the underlying pathologic lesion on the functional response of the remaining nephrons in a diseased kidney has received only limited attention. Sodium and water retention are clinical hallmarks of APGN while increased sodium excretion is described in pyelonephritis. Gonick et al. (17), and Kleeman et al. (18) found a higher proportion of salt wasters among patients with tubular than with glomerular disease while on a low salt diet. However, recently, Schacht et al. $(5,19)$ reported increased sodium excretion after saline loading in patients studied months to years after an attack of acute poststreptococcal glomerulonephritis as compared to a control population. Although these authors describe persistent glomerular changes on repeat kidney biopsy, they do not comment on the presence or extent of interstitial or tubular damage (19).

In their exposition of the "intact nephron hypothesis," Bricker et al. (15) emphasized the similarities and minimized the differences in glomerulotubular balance between the chronically diseased and control kidney in animals with unilateral disease. However, the base-line $F E_{\mathrm{Na}}$ is actually significantly higher for the pyelonephritic kidney than control kidney even though the differences are small (11). The absolute difference in FE between the pyelonephritic and control kidney is approximately the same as the absolute difference in $\mathrm{FE}_{\mathrm{Na}}$ between the kidney with APGN and intact kidney in group I, although in opposite directions. These differences are exaggerated by volume expansion suggesting that the degree of volume expansion is important in determining similarity of whole kidney glomerulotubular balance for sodium in the diseased and control kidney in both of these models. Thus the differences appear to be significant, not so much during stable base-line conditions, but whenever the animal receives a natriuretic stimulus. Nevertheless, the degree of similarity of glomerulotubular balance for the APGN and intact kidney under base-line conditions is remarkable considering the marked pathologic alterations in the APGN kidney.

Postglomerular oncotic pressure, as indicated by the filtration fractions, cannot explain the difference in baseline sodium excretion between the APGN kidney and intact kidney in group I although it might conceivably do so in the group II dogs. It is of interest in this regard that Maddox et al. (20) recently reported that absolute and fractional fluid reabsorption in the proximal tubule of rats with mild nephrotoxic nephritis and a normal single nephron GFR, but a decreased filtration fraction, were less than in control rats. The changes in filtration fraction induced by volume expansion in the APGN kidney in groups I and II also do not parallel the different patterns of sodium excretion. However, filtration fractions must be interpreted with caution in these dogs until more information is available regarding $\mathrm{PAH}$ extraction ratios. It is also conceivable that creatinine could leak out of the damaged nephrons thereby giving both a falsely low GFR and filtration fraction. Allison et al. (8), however, could find no indication of this using inulin for GFR measurement.

We have previously reported the pyelonephritic kidney in the unilateral dog model to be more sensitive to alterations in hydrostatic and oncotic pressure than the contralateral control kidney suggesting that changes in internal milieu of the diseased kidney are responsible for this increased sensitivity to changes in Starling forces (21). These studies, along with our present observations, support the concept that the pathological alterations within the kidney are responsible for its ultimate functional pattern. However, they do not definitively exclude the elaboration of a locally released antinatriuretic substance or increased degradation of (or unresponsiveness to) a natriuretic substance by the kidney with APGN of mild degree. They also do not exclude an increased sensitivity of the more severely damaged kidney with APGN, chronic glomerulonephritis, or pyelonephritis to a natriuretic substance. Finally, the intact nephron hypothesis applies in a limited fashion to kidneys with acute proliferative glomerular disease under base-line conditions, just as it does for kidneys with chronic glomerulonephritis or pyelonephritis. The similarity of whole kidney glomerulo-tubular balance for sodium in the diseased and contralateral control kidneys in the dog model with unilateral disease is largely determined by the degree of extracellular fluid volume expansion.

\section{REFERENCES}

1. Earle, D. P., S. J. Farber, J. D. Alexander, and E. D Pellegrino. 1951. Renal function and electrolyte metabolism in acute glomerulonephritis. J. Clin. Invest. 30: 421-433.

2. Earle, D. P. 1967. Physiologic abnormalities in acute glomerulonephritis. In Acute Glomerulonephritis. J. Metcoff, editor. Little, Brown \& Co., Inc., Boston. 1: 301-317.

3. Farber, S. J. 1957. Physiologic aspects of glomerulonephritis. J. Chronic. Dis. 5: 87-107.

4. Bruck, E., M. Rapoport, and M. I. Rubin. 1954. Renal functions in the course of the nephrotic syndrome in children. J. Clin. Invest. 33 : 699-723. 
5. Schacht, R. G., J. M. Steele, Jr., and D. S. Baldwin. 1974. Exaggerated natriuresis in the course of poststreptococcal glomerulonephritis. Nephron. 13: 349-364.

6. Lubowitz, H., D. C. Mazumdar, J. Kawamura, J. T. Crosson, F. Weisser, R. Rolf, and N. S. Bricker. 1974. Experimental glomerulonephritis in the rat: Structural and functional observations. Kidney Int. 5: 356-364.

7. Mazumdar, D. C., J. T. Crosson, and H. Lubowitz. 1975. Glomerulo-tubular relationships in glomerulonephritis. J. Lab. Clin. Med. 85: 292-299.

8. Allison, M. E. M., C. B. Wilson, and C. W. Gottschalk. 1974. Pathophysiology of experimental glomerulonephritis in rats. J. Clin. Invest. $53: 1402-1423$.

9. Godon, J. P. 1972. Sodium and water retention in experimental glomerulonephritis. Kidney Int. 2: 271-278.

10. Wagnild, J. P., F. D. Gutmann, and R. E. Rieselbach. 1974. Functional characterization of chronic unilateral glomerulonephritis in the dog. Kidney Int. 5: 422-428.

11. Gutmann, F. D., and R. E. Rieselbach. 1971. Disproportionate inhibition of sodium reabsorption in the unilaterally diseased kidney of dog and man after an acute saline load. J. Clin. Invest. 50: 422-431.

12. Wagnild, J. P., F. D. Gutmann, and P. M. Burkholder. 1973. Unilateral glomerulonephritis in the split bladder dog: Technique of induction and morphologic changes. Lab. Invest. 29 : 642-651.

13. Desautels, R. E. 1957. Hemisection of the bladder for the collection of separate urine samples. Surg. Gynecol. Obst. 105 : 766-768.

14. Beeson, P. B., H. Rocha, and L. B. Guze. 1957. Experimental pyelonephritis: Influence of localized injury in different parts of the kidney on susceptibility to hematogenous infection. Trans. Assoc. Am. Physicians Phila. 70: 120-126.

15. Bricker, N. S., S. Klahr, H. Lubowitz, and R. E. Rieselbach. 1965. Renal function in chronic renal disease. Medicine (Baltimore). 44: 263-288.

16. Rieselbach, R. E., L. Todd, M. Rosenthal, and N. S. Bricker. 1964. The functional adaptation of the diseased kidney. II. Maximum rate of transport of $\mathrm{PAH}$ and the influence of acetate. J. Lab. Clin. Med. 64: 724-730.

17. Gonick, H. C., M. H. Maxwell, M. E. Rubini, and C. R. Kleeman. 1966. Functional impairment in chronic renal disease. I. Studies of sodium-conserving ability. Nephron. 3: $137-152$.

18. Kleeman, C. R., R. Okun, and R. J. Heller. 1966. The renal regulation of sodium and potassium in patients with chronic renal failure (CRF) and the effect of diuretics on the excretion of these ions. Ann. N. Y. Acad. Sci. 139: 520-539.

19. Baldwin, D. S., M. C. Gluck, R. G. Schacht, and A. Moussalli, and G. R. Gallo. 1973. Long-term follow-up of poststreptococcal glomerulonephritis. In Glomerulonephritis. P. Kincaid-Smith, T. H. Mathew, and E. L. Becker, editors. John Wiley \& Sons, Inc., New York. $1: 327-343$.

20. Maddox, D. A., C. M. Bennett, W. M. Deen, R. J. Glassock, D. Knutson, and B. M. Brenner. 1975. Control of proximal tubule fluid reabsorption in experimental glomerulonephritis. J. Clin. Invest. 55 : 1315-1325.

21. Wagnild, J. P., F. D. Gutmann, and R. E. Rieselbach. 1974. Influence of hydrostatic and oncotic pressure on sodium reabsorption in the unilateral pyelonephritic dog kidney. Clin. Sci. Mol. Med. 47 : 367-376. 